\title{
Appreciating complexities, changing contexts and accountability challenges in sexual and reproductive health rights
}

\section{SANA CONTRACTOR}

\begin{abstract}
Social accountability is fast being recognised as an important strategy for realisation of sexual and reproductive health rights. However, the predominant approach tends to focus on use of top-down monitoring and accountability tools that do not capture the complexity of politics surrounding this deeply contested terrain. This paper draws on discussions that took place at the Community of Practitioners on Accountability and Social Action in Health (COPASAH) Global Symposium in October 2019 where grassroots practitioners shared their experiences of seeking accountability and reflected on the myriad challenges in this process. The paper calls for greater nuance and awareness of context in the design and implementation of social accountability interventions, which engage with power and politics between the forces that determine people's access to SRH rights.
\end{abstract}

Keywords: Social accountability, sexual and reproductive health rights, democratic governance, community participation, citizen-led accountability

\section{Introduction}

Sexual and reproductive health rights (SRHR) are an indivisible part of human rights, and an essential component of public health services. Some areas of SRHR have been included in the past as part of the Millennium Development Goals (MDGs) and continue within the existing framework of Sustainable Development Goals (SDGs), whereas others remain largely unaddressed. The focus of policies and programmes has been chiefly on maternal health and family planning, while important concerns around access to contraception, safe abortion, sexuality education, and sexual health needs of diverse populations have been neglected. More attention needs to be directed towards women's autonomy and participation, and their access to affordable quality healthcare for a larger

Author: Sana Contractor (sanacontractor@gmail.com), Co-Convenor, COPASAH Sexual and Reproductive Health Hub, Centre for Health and Social Justice, Basement of Girls Hostel no. 2, Avenue 21, G Block, Saket, near Bank Of India, New Delhi 110017 INDIA

To cite: Contractor S. Appreciating complexities, changing contexts and accountability challenges in sexual and reproductive health rights. Indian J Med Ethics. 2021 Oct-Dec; 6(4) NS: 286-90. DOI:10.20529/IJME.2021.076

Manuscript Editor: Sunita VS Bandewar

Peer Reviewer: Akhila Vasan

(c) Indian Journal of Medical Ethics 2021 range of SRH services.

While the idea of accountability has gained momentum through international mechanisms, the main understanding of accountability among large agenda-setting organisations in this field is "upward accountability" to donors rather than public accountability to women. The predominant approach of the monitoring and accountability mechanisms associated with global initiatives like the MDGs, SDGs and Family Planning 2020 (FP2020), involves a top-down monitoring of quantitative targets at higher levels. The process of determining and monitoring these targets does not include substantive participation of women and communities who "receive" these programmes, and does not accommodate emerging concerns as contexts change. The pursuit of targets has also, in some instances, led to ethical violations including concerns around coercion, choice and acceptability. However, various citizen action groups have been involved in raising concerns around $\mathrm{SRH}$ on the ground, including social movements, grassroots organisations and citizen's collectives.

\section{The theme of SRHR at the COPASAH Global Symposium}

This paper draws on discussions that took place within the sexual and reproductive health rights theme at the Global Symposium on Citizenship, Governance and Accountability in Health which was organised by Community of Practitioners on Accountability and Social Action in Health (COPASAH), a southern-led, global community of grassroots practitioners of social accountability and community action in the field of health. It is a leading voice in discussions on community-centred and citizen-led processes in the field of health. This Symposium brought together field practitioners largely from the global South engaged in long term community-led accountability practice as well as researchers, policy-makers, donors and other stakeholders to address challenging questions of practice and discussing strategies to realise sexual and reproductive health and rights. Sharing of practice, identifying emerging models of engagement with state and non-state actors, their strengths and weaknesses, led to discussions about the unique challenges that working on sexual and reproductive health and rights poses in the field of social accountability.

\section{Emerging conversations}

Primarily, four arcs of conversation emerged which 
exemplified and interrogated current practice in the field of accountability and SRH rights.

\section{Appreciating complexity and dynamism in contexts and its implications for SRHR accountability}

Sexual and reproductive health rights are deeply contested all over the world. This conflict is rooted in patriarchal control of women's bodies, but the nature of violations, and policies that impact them take different forms across contexts and across times. This was demonstrated in the challenges that participants posed to realising SRH rights in their particular contexts. In China, for instance, public policy on contraception has moved from enforcing the "one-child norm" to now allowing a larger family, but concerns over the state's control of women's fertility continue (1). The experience from Uganda suggests that the struggle for access to contraception faces challenges and taboos from socially conservative communities and policy makers alike (2). Similarly in India, while access to contraception is a challenge for young unmarried persons especially adolescents, contraception is often thrust upon women with two or more than two children through coercive means. Moreover, patriarchal forces interact with other axes of power to target certain groups of women, such as in parts of Europe, where forced and coerced sterilisation of Roma women is widely prevalent (3).

At the heart of these realities, however, is the fundamental aspect of control of women's bodies and fertility, and using this lens can help to analyse the appropriateness of strategies. This implies that social accountability practice must have common goals (the preservation of safety, autonomy and dignity) but different immediate outcomes for different groups. In India, for instance, influencing policy and healthcare providers to make contraceptives available to young people, while at the same time monitoring the implementation of "informed choice" for married women are both outcomes of the accountability strategy.

Moreover, the strategies themselves will be different across locations and at different times. In Romania for instance, resisting forced and coerced sterilisation through legal means and policy negotiation are both an important part of accountability strategies. The temptation to implant solutions from one context to the other must therefore be resisted, as must the setting of meta-indicators alone, to monitor progress.

Further, accountability practice, in a deeply contested field like sexual and reproductive health rights, must engage with various levels of the state (from policy and politics, to health facilities at the frontline of health service provision) and must acknowledge the complex nature of the "State" and the varying political contexts. In China for instance, an organisation has been addressing SRH rights largely through public education campaigns, since the state is more or less closed to negotiation. As the practitioner from China framed it, "pro-choice and pro-life are western notions of individual choice; in China, however, everyone is expected to be pronation, and what this means in terms of action varies depending on government policy". In such a situation, accountability actions have to be directed towards specific contexts and have different goals. Given the dynamic and contextual nature of SRH rights, therefore, it is imperative that practitioners continuously examine how shifts in policies and programmes intersect with local realities and landscapes.

\section{Negotiating the power of global accountability mechanisms}

Over the past two decades, certain issues pertaining to $\mathrm{SRH}$, like maternal health and family planning, have received a great deal of attention, with large global health initiatives focusing on these which has contributed to narrowing and verticalisation of the SRH agenda. Along with this, there has been a proliferation of accountability mechanisms with many international agencies, bilateral donors and private philanthropies providing funds to governments to reach targets. These mechanisms provide space for civil society organisations to participate. For instance, the FP2020 has a "performance monitoring and evidence" working group (4) and the Partnership for Maternal Neonatal and Child Health (PMNCH) of the WHO has an "accountability working group" (5) with civil society representation. While access to these spaces is available largely to international organisations and large funded organisations, some rightsbased networks have been using them to advance a rightsbased SRH agenda and represent local realities at these forums. The Equal Measures 2020 initiative for instance, has developed a Gender Equity Index to raise critical concerns about SRH among other gender related issues at SDG platforms (6).

Organisations like Centre for Reproductive Rights have been litigating in bodies such as the European Court of Human Rights, and the UN human rights committee on issues of adolescent health rights and abortion rights $(7,8)$. Other civil society regional networks and disability rights groups such as the Women With Disabilities India Network, have used UN covenants such as Convention on the Elimination of All Forms of Discrimination against Women (CEDAW), Convention for Rights of People with Disabilities (CRPD) to highlight specific SRH concerns of diverse women (9).

Despite important gains that these efforts have led to, practitioners discussed their struggles in attempting to link local community realities with these global accountability mechanisms and the strategies that they have adopted. The discussion highlighted inherent challenges in engaging with these mechanisms, such as the disconnect with grassroots realities and lack of receptivity of governments to recommendations from these forums. Regarding the overall 
effectiveness of these mechanisms, the experience has been variable. While some efforts have made important issues (like rights of disabled persons, for instance) visible, others like the voluntary national reporting of SDGs is not as effective, as it can easily be ignored by the governments because it is entirely voluntary, unlike processes such as the Universal Periodic Review ${ }^{1}$.

Practitioners highlighted the importance of linking these global mechanisms to local realities through involvement of grassroots activists, rather than international organisations. Further, they emphasised that it was important to recognise the limitations of these mechanisms especially their structural power dynamics and potential to reinforce topdown pressures. Any efforts at the global level, therefore, need to supplement bottom-up accountability efforts at the local, sub-national and national levels.

\section{Addressing new accountability challenges posed by the growth of the private sector}

In the field of sexual and reproductive health, the growing dominance of the profit-driven private sector in provision of health services and production of health commodities has led to new forms of violations ranging from medically unwarranted medical procedures (such as unwarranted hysterectomies), over-use of certain procedures (such as Csections), poor quality of care to larger questions of a growing industry of interventions on women's bodies. The rights-based network Karnataka Janaarogya Chaluvali has been actively calling to account the private sector for large scale hysterectomies that have been conducted on indigenous women in the state of Karnataka in India (10). The strategies have been multi-layered, including building credible evidence on the nature of violations, mobilising women to demand accountability for the violations, using media and putting pressure on the government to take action against erring establishments. The challenge however has been in enforcing accountability in a context of gross lack of regulation of the private health sector across India; and a concerted opposition to such regulation by medical associations. The other aspect of corporate growth that deserves attention is that of regulating reproductive health products. While the advancement of technology provides greater opportunities for women to make choices on the one hand, there is a growing threat of over medicalisation and dumping of reproductive products onto women especially on women from the global South. This is especially true in the area of contraceptives where the focus of health programmes in many countries and also that of global health initiatives is to increase uptake of contraceptives without due consideration to side effects and health consequences for women who use them. Further, introduction of "self-care" in reproductive health packages raises new challenges about accountability, especially in situations where a weak public health system is unable to monitor or hold the violators to account.

\section{Addressing social hierarchies through SRHR accountability work}

The struggle for realising sexual and reproductive rights is deeply influenced by gender-related social norms and various axes of inequities and injustice prevalent in societies. The symposium participants explained how these inequities influence sexual and reproductive health rights, and what elements must form a part of accountability practice, at the interface of communities with health systems, and also within health systems and communities themselves. At the heart of the accountability deficit is the power differential and systemic bias that allows health systems to provide inadequate, poor quality or negligent care to those from less privileged backgrounds, and perpetrate violations with impunity. Women, especially those from socially excluded and marginalised communities face the brunt of this, and social accountability interventions must work to transform this skewed relationship. Participants repeatedly stressed the importance of embedding social accountability practice within larger rights-based struggles of social movements and the constitutional idea of democratic citizenship. The Jagrutha Mahila Sangathan, a grassroots Dalit women's movement in India, located its work on demanding accountability for respectful and good quality maternal health services, within a long-standing struggle against caste-based violence against women spanning over two decades. The women involved in the movement came together owing to a common experience of violence against Dalit women by the upper castes in rural north Karnataka (11: $p$ 5). Over two decades of consciousness raising, the women have attempted to address state apathy to their needs. Within this struggle, the movement for respectful maternal care has specifically demanded that healthcare providers treat Dalit women with dignity and be responsive to their needs. Another practice presented by the YP Foundation that used scorecards to assess the friendliness of health services to young people and adolescents from deprived backgrounds, was rooted in a three decade-long grassroots movement by Action India that sought to mobilise urban poor women to demand gender justice and various social and economic rights (11: $p$ 5). There is a need to nurture such sustained struggles to truly transform relationships between the powerful and powerless, as opposed to induced, bounded interventions that are typical of mainstream social accountability practice.

\section{Implications for practice}

A rights-based approach to social accountability situates accountability within the paradigm of democratic citizenship, and seeks to mediate the relationship between citizens and public systems, recognising the imbalance of power between the two. When it centres on the needs and aspirations of the most marginalised, it can be powerful for negotiating sexual and reproductive health rights, provided that social accountability interventions "confront power relations, improve the representation of marginalised 
groups and transform them in legitimising ways" through information, dialogue and negotiation (12). Moreover, social accountability can generate new norms around healthseeking behaviours by educating communities about their health rights and mobilising them to take action (13). This is particularly beneficial in the case of reproductive health, where health outcomes are dependent not just on health system strengthening, but also on transformation of gender norms related to health-seeking.

However, the predominant approach to social accountability in public health, and SRH in particular, restricts itself to guaranteeing implementation of programmes, policies and entitlements from the State, and not questioning the policies and programmes themselves. Historically global policies and trends that dictate and hold power over national policy making are often removed from community realities. In the domain of reproductive health especially, this takes on great significance because women, by virtue of being disempowered have been typically seen as passive recipients of medical reproductive health interventions, sometimes against their will. For instance, North-South imbalances in power fuelled by a fear of "population explosion" have often handed down policies such as population control, coercing and sometimes forcing marginalised women into unwanted procedures. At a grassroots level, the situation is further complicated by the fact that people most affected by such policies tend to be marginalised "non-citizens" whose power of negotiation with the system is negligible (14).

Over the past two decades, there has been a proliferation of interventions for social accountability in public health and in the SRH field in particular. Yet, as a systematic review points out, the evidence emanating from these interventions does not sufficiently capture the complexity of contexts in which they are implemented, and the ways in which this impacts accountability (15). The insights from practitioners in this symposium substantiate the importance of taking into account such diversity of political and social contexts that determine how axes of power operate with patriarchal systems, giving rise to violations in SRH. It challenges the one-size-fits all formulations of social accountability, and reiterates the importance of appreciating the complexity of both systems, as well as communities across contexts. Unlike the proliferation of bounded, induced interventions in the field of social accountability, the insights from the symposium emphasise the need to embed this practice within long standing social movements. The discussions on proliferation of the private sector and its evasion of accountability and the limitations posed by global accountability mechanisms open up challenging new areas for research and action. They emphasise the need to go beyond demanding accountability at the most grassroots level between service providers and health workers, to challenging power at sub-national, national and global levels including from non-state actors.

\section{Conclusions}

Ethical violations in SRH have the potential to be addressed through strengthening bottom-up accountability, through collective action. In a global context where accountability is seen as a tool of "good governance", there is a critical need for accountability to be re-politicised, to give primacy to community autonomy and be cognisant of complexities. There is a rich practice of organising around reproductive rights in the global South that warrants attention from researchers and has much to teach us about how change can be achieved.

Acknowledgements: The author would like to acknowledge the inputs of Marta Schaaf and Jashodhara Dasgupta who participated in identifying the themes and curating the SRH track in the symposium.

\section{Note:}

'The Universal Periodic Review is a mechanism instituted by the Human Rights Council which involves a periodic review of the human rights records of all 193 UN Member States. It offer opportunities for NGOs to file in alternative "shadow" reports on government progress towards realising sexual and reproductive health and rights.

\section{References}

1. Kuo L. China: new rules to prevent sex-selective abortions raise fears. Guardian 2018 Jun 22[cited 2021 Sep 13]. Available from: https://www.theguardian.com/world/2018/jun/22/china-new-rulesjiangxi-province-prevent-sex-selective-abortions

2. Boydell V, Nulu N, Hardee $\mathrm{K}$, et al. Implementing social accountability for contraceptive services: lessons from Uganda. BMC Women's Health. 2020;20: 228. https://doi.org/10.1186/s12905-02001072-9.

3. Albert G, Szilvasi M. Intersectional discrimination of Romani women forcibly sterilized in the former Czechoslovakia and Czech Republic. Health Hum Rights. 2017 Dec 1; 19(2): 23-34.

4. Family Planning 2020. The Performance Monitoring and Evidence Working Group. FamilyPlanning2020.org. Date unknown [cited 2021 Sep 13]. Available from: https://www.familyplanning2020.org/ performance-monitoring-and-evidence-working-group

5. PMNCH, World Health Organization. Accountability Working Group. Date unknown [cited 2021 Sep 13]. Available from: https:// pmnch.who.int/about-pmnch/how-we-are-governed/workinggroups/accountability

6. SDG Gender Index/ Equal Measures Initiative. Key Findings. Date unknown [cited 2021Sep 13]. Available from; https:// data.em2030.org/2019-sdg-gender-index/key-findings/

7. Center for Reproductive Rights. P. and S. v. Poland (European Court of Human Rights). 2008 Nov 18[cited 2021 Sep 13].Available from: https://reproductiverights.org/case/p-and-s-v-poland-europeancourt-of-human-rights/

8. Center for Reproductive Rights. Press Release. U.N. Committee Finds Ireland's Abortion Laws Are Cruel, Inhumane and Degrading. 2016 Jun 10[cited 2021 Sep 13]. Available from: https:// reproductiverights.org/u-n-committee-finds-irelands-abortionlaws-are-cruel-inhumane-and-degrading/

9. Women with Disabilities India Network. Submission of alternative report (Article 6) to the Committee on the Rights of Persons with Disabilities: India. 2019 Feb10[cited 2021Sep 13]. Available from: https://tbinternet.ohchr.org/Treaties/CRPD/Shared\%20Documents/ Ind/INT_CRPD_ICO_Ind_33879_E.docx

10. Xavier T, Vasan A, Vijayakumar S. Instilling fear makes good business sense: unwarranted hysterectomies in Karnataka. Indian J Med Ethics. 2017 Jan-Mar; 2(1) NS:49-55. Doi: 10.20529/IJME.2017.010.

11. COPASAH Global Symposium 2019. Dismantling social hierarchies through SRHR work. Thematic Session I- 2019 Oct 16[cited 2021 Sep 13]. Available from: https://www.copasahglobalsymposium2019.net/ uploads/1/2/6/4/12642634/final_thematic_3.pdf

12. George A. Using accountability to improve reproductive health care, 
Reprod Health Matters. 2003;11(21): 161-70. Doi: 10.1016/S09688080(03)02164-5.

13. Malena C, Forster R, Singh J. Social accountability: An introduction to the concept and emerging practice. Social Development Paper No. 76. Washington, DC: World Bank; 2004.

14. Schaaf M, Dasgupta J. "Our fear is finished," but nothing changes: efforts of marginalized women to foment state accountability for maternal health care in a context of low state capacity. BMC Public Health. 2019;19,:732. https://doi.org/10.1186/s12889-019-7028-2.

15. Boydell V, Schaaf M, George A, Brinkerhoff DW, Van Belle S, Khosla R. Building a transformative agenda for accountability in SRHR: lessons learned from SRHR and accountability literatures. Sex Reprod Health Matters. 2019; 27(2):64-75. Doi: 10.1080/26410397.2019.1622357

\title{
Examining women's health through a psychosocial lens
}

\author{
SATHYASREE GOSWAMI
}

\begin{abstract}
During the COPASAH Global Symposium 2019, a group of therapists and mental health practitioners tried to highlight the issue of women's mental health with two specific focuses, one being the lived experiences of persons living with mental illness and the secondary burn-out and shame faced by their caretakers. The second session explored the contours of somatisation that is often seen in the human body as a result of the impact of trauma. The participants reflected on the value of lived experiences and also discussed the challenges faced in getting representation for people living with mental illness. The challenges listed by participants were concentrated around the participation and representation of persons living with intellectual disability and psychosocial disability. Somatisation of traumatic experiences needs recognition in a country like India where women's life-stressors exist right from childhood that keeps them on the threshold of mental illness and/or psychosomatic illnesses. Psychosocial health issues are relegated to a subordinate category of discussion while public health, reproductive health, and health rights feature in mainstream discussions in various seminars, researches and conferences in India. This paper is based on two sessions of the COPASAH Global Symposium 2019 and focuses on the gender and psychosocial dimensions of health from the framework of women being subjected to unpaid care work, through social and reproductive labour and stressors resulting in psycho-social
\end{abstract}

Author: Sathyasree Goswami (g.sathyasree@gmail.com), Doctoral Scholar, Tata Institute of Social Sciences, Deonar, Mumbai, INDIA.

To cite: Goswami S. Examining women's health through a psychosocial lens. Indian J Med Ethics. 2021 Oct-Dec; 6(4) NS: 290-93. DOI: 10.20529/IJME. 2021.077

Manuscript Editor: Sunita VS Bandewar

Peer Reviewers: Sadhana Natu

(c) Indian Journal of Medical Ethics 2021 distress. To this end, it is important to build a community of practitioners that looks beyond the reproductive health of women.

Keywords: Women's health, somatisation, psycho-social wellbeing

\section{Introduction}

It is still taboo in India to seek support for mental health distress. A nationwide survey on mental illness in India estimated that about 150 million adults over the age of 18 years are in need of mental healthcare (1). As the Sustainable Development Goals (SDGs) have generically clubbed mental illness under non-communicable diseases and substance abuse (2), attention needs to be focused on the need to consider the sociopolitical-cultural contexts of people with psychosocial disabilities. Women with psychosocial disabilities (PSD) face greater vulnerability and are subjected to increased stigma and discrimination. Additionally, it is also transpersons, poor women, female sex workers, and queer women, who face greater barriers in the exercise of their political and civil rights.

According to the World Health Organization (WHO) (3), gender differences are seen in the prevalence rates of common mental disorders like depression, anxiety and somatic complaints. It is understood that women predominate in numbers in common mental disorders and this is considered to constitute a serious public health problem. However, little or no focus is seen on transpersons, poor women, female sex workers, queer women's PSD issues. In the practitioner's huddle during the symposium, a participatory session outlined the importance of listening to people with lived experience of PSD and engaging with them in community-based prevention and therapy practices.

The Symposium also had a session to understand the somatic $^{1}$ repercussions of stress and trauma, especially those 